Research Article

\title{
Use of complementary and alternative medicines by patients with orthopaedic disorders in western part of India: a cross sectional study
}

\author{
Nayna J. Gohil, Varsha J. Patel*
}

Department of Pharmacology, NHL Municipal Medical College, Ahmedabad, India

Received: 21 July 2016 Accepted: 13 August 2016

*Correspondence to:

Dr. Varsha J. Patel,

Email: drvarsha4@ rediffmail.com

Copyright: () the author(s), publisher and licensee Medip Academy. This is an openaccess article distributed under the terms of the Creative Commons Attribution NonCommercial License, which permits unrestricted noncommercial use, distribution, and reproduction in any medium, provided the original work is properly cited.

\begin{abstract}
Background: Complementary and alternative medicines (CAM) are consumed all over the world for variety of health problems. This study was aimed at assessing the prevalence and pattern of CAM in patients with orthopaedic disorders.

Methods: This cross sectional study was carried out at outpatient department of Orthopaedics at a tertiary care teaching hospital. Data was collected with help of questionnaire which contained sociodemographic details and details of use of CAM if any by the attending patients. Data was analysed for sociodemographic and clinical characters, pattern of use of CAM, source of information and reasons for using CAM.

Results: Out of 500 participants 196 (39.2\%) reported use of CAM. Mean age of participants was $42.6 \pm 19.8($ mean \pm SD) years and $130(66.3 \%)$ users were women. Illiterate patients $(57 \%)$ were the most frequent users of CAM. About $77 \%$ of patients aged 60 years and above used CAM. Fibromyalgia (48\%) was the commonest condition for CAM use. Folk medicines $(46 \%)$ and ayurvedic medicines $(45 \%)$ were most commonly used CAM. Advice from friends/relatives was the commonest source of information. None of the respondents had knowledge of adverse effects of CAM used by them and about $70 \%$ did not inform their doctor about use of CAM.

Conclusions: Use of CAM is highly prevalent in patients with orthopaedic disorders, women, illiterate and elderly being the more likely users. Concurrent use of folk remedies with allopathic medicines has potential for interactions between the two. History of use of CAM should be obtained as a routine from patients with musculoskeletal complaints.
\end{abstract}

Keywords: Complementary medicine, Alternative medicine, CAM, Drug use study, Musculoskeletal disorder

\section{INTRODUCTION}

The National Centre for Complementary and Alternative Medicine (NCCAM) defines CAM as a group of diverse medical and health care systems, practices and products that are not presently, considered to be a part of conventional medicine. ${ }^{1}$ Complementary medicine is used together with conventional medicine while Alternative medicine is used in place of conventional medicine. ${ }^{1}$

Studies have documented that about half the population of many industrialized countries use traditional, complementary and alternative medicine and the proportion is as high as $80 \%$ in many developing countries. $^{2}$ It is being widely used in India and about 2860 hospitals provide CAM services. ${ }^{3,4}$ Herbal medicines are increasingly becoming popular as alternative medicines and estimated one third adult population from developing countries and $80 \%$ from developed countries are using herbs as an alternative medicines often in combination with allopathic drugs which may lead to herb drug interaction by affecting pharmacokinetic and / or pharmacodynamic properties. ${ }^{5}$

Rheumatologic diseases are chronic and usually progressive conditions cause pain, physical disability and dependence on medications which do not always provide 
full symptom relief. Previous studies have revealed that the use of CAM is prevalent among patients with rheumatic diseases, with the frequency of CAM use being reported as between $22 \%$ to $96.8 \%$ depending on the country. ${ }^{6-8}$

Limited information about utilisation pattern of CAM in musculoskeletal disorders is available in India. Hence this study was planned with the aim of assessing the prevalence and pattern of the utilization of CAM in Out Patient Department of Orthopaedics at a tertiary care teaching hospital in Western part of India in Gujarat state.

\section{METHODS}

This was a questionnaire based cross sectional descriptive study. The study was carried out in out-patient Department of Orthopaedics at C.U. Shah Medical College and Hospital in Surendranagar city of Gujarat state in India. The CU Shah hospital is a teaching hospital in Surendranagar catering to health needs of people in villages in Zalavad province as well as the Surendranagar city. The study was approved by the Institutional Ethics committee. The study period was August 2010 to November 2010 (three months). Patients of both sex and all age groups attending outpatient department of Orthopaedic surgery during study period were invited to participate. All the patients were informed about the study and its aim. Those patients who were willing to participate and consented for the study were included. A questionnaire to assess the prevalence and pattern of use of CAM was developed and validated by considering previous study. ${ }^{9}$ The questionnaire was pre- tested by pilot study in 20 patients. Modifications were made based on the responses and observations of the patients.

Questionnaire was filled in either by participants themselves or by investigator by asking questions to the illiterate patients and parents or guardians in case of children. Questionnaire included information regarding sociodemographic data, present clinical condition, allopathic medicines used and details of usage of complementary and alternative medicine, sources of information for CAM, the reasons for CAM use and participant's knowledge of adverse drug reactions likely to occur with CAM.

For usage of complementary and alternative medicine patients were specifically asked about different CAM therapies including herbal remedies from Ayurveda, homeopathy, folk remedies, acupuncture, chiropractic, megavitamins, prayer or spiritual healing, commercial diet programs, relaxation, meditation, massage, naturopathy, yoga etc. If patients were using CAM then further questions regarding CAM were asked.

Most of the allopathic drugs were prescribed by their brand names. The generic content of each formulation was obtained from commercial publications like Indian Drug Review (IDR). Information regarding herbal or any alternative medicine was obtained from commercial web site (www.nccam.nih.gov). Information not available from this source was obtained from local medicine shops.

\section{Sample size calculation}

Sample size of 285 was derived using Raosoft sample size calculator considering prevalence of $25 \%$ at $95 \%$ confidence with $5 \%$ margin of error. ${ }^{10}$ Data were analysed by using Microsoft excel 2007.

\section{RESULTS}

\section{Prevalence of use of CAM}

Total 500 patients were included in this study. Out of 500 patients 196 (39.2\%) reported using CAM, 34(17.35\%) being current users. Out of 196 CAM users, $130(66.3 \%)$ were female. Mean age of participants was $42.6 \pm 19.8$ $($ mean \pm SD) years. Illiterate patients reported most frequent use of CAM with $57 \%$ while graduates reported lowest use at $25 \%$.

Table 1: Demographic characteristics of study population $(\mathrm{N}=\mathbf{5 0 0})$.

\begin{tabular}{|lllll|}
\hline Variable & & Number $(\%)$ & CAM users $(\%)$ & Prevalence $(\%)$ \\
\hline Gender & Male & $251(50.2)$ & 66 & 26.29 \\
\hline Age (years) & Female & $249(49.8)$ & 130 & 52.21 \\
\hline & $<10$ & $37(7.4)$ & 1 & 2.70 \\
\hline & $11-20$ & $48(9.6)$ & 9 & 18.75 \\
\hline & $21-30$ & $62(12.4)$ & 14 & 22.58 \\
\hline & $31-40$ & $76(15.2)$ & 26 & 34.21 \\
\hline & $41-50$ & $91(18.2)$ & 30 & 32.96 \\
\hline & $51-60$ & $95(19)$ & 46 & 48.42 \\
\hline & $>60$ & $91(18.2)$ & 70 & 76.92 \\
\hline & Hindu & $458(91.6)$ & 182 & 39.73 \\
\hline
\end{tabular}




\begin{tabular}{|lllll|}
\hline & Christian & $0(0)$ & 0 & 0.00 \\
\hline & Other & $0(0)$ & 0 & 0.00 \\
\hline Monthly family Income (Rs.) & $<5000$ & $368(73.6)$ & 141 & 38.31 \\
\hline & $5000-10000$ & $78(15.6)$ & 34 & 43.58 \\
\hline & $>10000$ & $58(11.6)$ & 21 & 36.20 \\
\hline Education & Illiterate & $54(10.8)$ & 31 & 57.40 \\
\hline & Can read/write & $198(39.6)$ & 75 & 37.87 \\
\hline & Up to school level & $200(40)$ & 78 & 39 \\
\hline & Graduates & $48(9.6)$ & 12 & 25 \\
\hline Background & Rural & $275(55)$ & 107 & 38.90 \\
\hline & Semi-urban & $106(21.2)$ & 35 & 30.17 \\
\hline & Urban & $119(23.8)$ & 54 & 43.37 \\
\hline
\end{tabular}

Table 2: Common conditions for which CAM was used $(\mathrm{N}=196)$.

\begin{tabular}{|ll|}
\hline Disease/symptoms & Number $(\%)$ \\
\hline Rheumatoid arthritis & $43(21.94)$ \\
\hline Osteoarthritis & $21(10.72)$ \\
\hline Fibromyalgia & $94(47.96)$ \\
\hline Other joint symptoms & $38(19.38)$ \\
\hline
\end{tabular}

Table 3: Characteristics of the individuals related to their use of CAM methods $(\mathrm{N}=196)$.

\begin{tabular}{|lll|}
\hline Characteristics & Number & Percent \\
\hline \multicolumn{1}{|l|}{ Type of CAM used } & \multicolumn{1}{l|}{} \\
\hline Ayurveda & 88 & 44.90 \\
\hline Homeopathy & 00 & 0.00 \\
\hline Unani & 00 & 0.00 \\
\hline Folk medicines & 91 & 46.43 \\
\hline Other & 17 & 8.67 \\
\hline Source of information about CAM usage & \\
\hline Qualified Practitioner & 00 & 0.00 \\
\hline Advice by friend/relatives & 129 & 66.33 \\
\hline TV/Internet/Media & 20 & 10.20 \\
\hline Self medicine & 46 & 23.47 \\
\hline Information to their doctor about CAM usage \\
\hline Yes & 59 & 30.10 \\
\hline No & 137 & 69.90 \\
\hline CAM Used associated with cost benefit \\
\hline Yes & 59 \\
\hline No & 137 \\
\hline Result experienced & 30.10 \\
\hline Beneficial & 69.90 \\
\hline Harmful & 190 \\
\hline No change & 0 & 96.94 \\
\hline Knowledge about side effects of CAM \\
\hline Yes & 0 & 0.00 \\
\hline No & 196 \\
\hline
\end{tabular}

Majority of CAM users were from urban area (45.4\%). About $77 \%$ of patients aged 60 years and above used CAM being the highest users (Table 1). Usage of CAM was most common in fibromyalgia $-47.96 \%$ followed by rheumatoid arthritis-21.94\% (Table 2).

Table 4: Distribution of CAM used orally $(N=42)$.

\begin{tabular}{|lll|}
\hline \multirow{3}{*}{ Medicine } & Disease & $\begin{array}{l}\text { No. of patient } \\
(\%)\end{array}$ \\
\hline \multirow{3}{*}{ Fenugreek seeds } & Fibromyalgia & $6(14.3)$ \\
\cline { 2 - 3 } & Osteoarthritis & $3(7.2))$ \\
\cline { 2 - 3 } & Rheumatic arthritis & $7(16.7))$ \\
\cline { 2 - 3 } Ginger powder & Total & $16(39.1)$ \\
\cline { 2 - 3 } & Osteoarthritis & $2(4.8)$ \\
\cline { 2 - 3 } Turmeric & Rheumatic arthritis & $2(4.8)$ \\
\hline \multirow{3}{*}{ powder } & Total & $5(4.9)$ \\
& Rheumatoid arthritis & $10(23.8)$ \\
\cline { 2 - 3 } & Osteoarthritis & $11(26.2)$ \\
\cline { 2 - 3 } & Low back pain & $1(2.4)$ \\
\cline { 2 - 3 } & Total & $22(52.4)$ \\
\hline
\end{tabular}

Table 5: CAM used topically $(\mathbf{N}=87)$.

\begin{tabular}{|ll|}
\hline Methods used & Number $(\%)$ \\
\hline Eucalyptus oil & $38(43.7)$ \\
\hline Mahanarayan oil & $12(13.8)$ \\
\hline Narayan oil & $26(29.9)$ \\
\hline Nirgundi oil & $10(11.5)$ \\
\hline Camphor & $1(1.2)$ \\
\hline
\end{tabular}

Friends/relatives $(66.33 \%)$ were the most common information source followed by self-experience $(23.47 \%)$. None of the patients had used CAM on recommendation by a qualified physician. About $30 \%$ of patients stated that they have used CAM because of cost benefit and $96.9 \%$ patients reported beneficial effects of CAM. None of the patients reported experiencing adverse effect after using CAM. About $70 \%$ of patients had not disclosed to their physician about the use of CAM. None of the patients had knowledge about side effects and possible drug interactions of CAM with prescription medicines.

Looking at the types of CAM used, majority (46.43\%) were using folk medicines followed by Ayurvedic medicines - $44.9 \%$ (Table 3). Eucalyptus oil - $19.39 \%$ 
was the most frequently used topical folk medicine followed by turmeric - $18.36 \%$, narayan oil $-13.27 \%$, mahanarayan oil - $6.12 \%$ and mustard oil $(5.61 \%)$. Among the orally used medicines by 42 patients, turmeric - $21 \%$ followed by fenugreek seeds $19 \%$ and dried ginger - 4\% were used. Other types of CAM reported were magnetic belt $(4.08 \%)$ and yoga $(3.57 \%)$.

\section{DISCUSSION}

Several studies have reported CAM use in disorders with musculoskeletal pain including knee arthritis, and rheumatoid arthritis. ${ }^{7,8,11,12}$ Varying prevalence of CAM use in rheumatic patients is reported from different countries-United States two third of respondents, Australia $40 \%$, Turkey $46 \%$ and India $58 \% .{ }^{13-15}$ In a study to define the relationship between medical skepticism and CAM use in two groups of individuals with musculoskeletal disorders; those being served by family practitioners and those served by specialists, $88 \%$ of the samples used some form of CAM for their pain related to musculoskeletal disorders. ${ }^{16}$ In our study about $39 \%$ patients had used CAM which is accordance with report from Australia. ${ }^{14}$ The low prevalence is due to inclusion of all types of orthopaedic disorders- acute as well as chronic.

Herman et al reported that the use of CAM methods was recommended to the majority of individuals by friends and relatives followed by qualified doctors. ${ }^{6}$ In our study about $66 \%$ patients had used CAM as advised by friends and family members followed previous use by self. Similar findings are reported from India. ${ }^{17,18}$ In this study only $30 \%$ patients had stated that CAM is less expensive, majority of patients had reported that CAM is natural, safe and having less adverse effects than allopathic medicine. Easy accessibility and efficacy were the other reasons.

Herman et al reported a higher use of CAM by patients with fibromyalgia and rheumatoid arthritis than those with osteoarthritis. ${ }^{6}$ Our findings are in accordance with these findings -CAM were used maximum (47.9\%) by patients with fibromyalgia followed by rheumatoid arthritis $(21.9 \%)$ and osteoarthritis $(10.7 \%)$ In a study at a tertiary care hospital in India, $39 \%$ of patients with rheumatoid arthritis reported current CAM use, higher than in our study. ${ }^{18}$

Our findings are also in accordance with Callahan et al, that majority of CAM were topical application. ${ }^{7}$ In our study ayurvedic medicines were used by $44.9 \%$ of the patients as the cost of therapy for Ayurveda is in general less than allopathy but more than house hold remedies which could be the reason for higher usage of house hold or folk remedies. These findings are in agreement with the Indian study by Zaman et al. ${ }^{18}$ Eucalyptus oil, mahanarayan oil, narayan oil, nirgundi oil were among common topical applications, eucalyptus oil being most frequently (19.4\%) used. Turmeric, fenugreek seeds and ginger were orally used herbs. Turmeric was most frequently orally used herb. Herman et al reported that magnets and copper bracelets were used by more than $1 \%$ of patients and Yoga was least frequently used CAM method. ${ }^{6}$ In our study $4 \%$ of the patients had used magnet belt and $3.6 \%$ of the patients had used Yoga to treat their arthritis. Acupuncture was the least frequently (1\%) used CAM method to treat their arthritis. This could be due to lack of awareness about these therapies in the region where study was carried out. Moreover use of CAM therapies varies from country to country depending upon their cultural beliefs regarding indigenous medicines being prevalent e.g. in China traditional Chinese medicine such as herbal medicine, acupuncture, acupressure, Qi gong and t'ai chi chu'an are widely used while in Japan kampong and acupuncture are commonly used CAM therapy. ${ }^{20}$

In a previous study majority $(90.4 \%)$ of patients had stated that CAM therapies were beneficial in treating arthritis and $22.6 \%$ never discussed their CAM use with their doctor. ${ }^{18}$ Majority of the respondents in our study (96.94\%) also reported beneficial effect. However in our study a higher proportion of CAM users $(70 \%)$ did not reveal CAM use to their doctors.

Use of CAM therapies is more common among women than men as in our study also 66\% CAM users were women. ${ }^{16,17,20}$ Callahan et al reported that approximately half of the participants had more than a higher school education. ${ }^{7}$ Herman et al reported that use of CAM therapies was positively associated with education. ${ }^{6}$ Our finding that majority $(57 \%)$ of users were illiterate is quite in contrast. National studies on CAM use among the general population found higher income was associated with CAM use. ${ }^{19,20}$ Herman et al had reported that their study and some other arthritis CAM studies found no association between CAM use and income. ${ }^{6}$ In our study high proportion $(43.58 \%)$ of CAM users had low monthly income. Easy access and lower cost of CAM can be the reasons. A study from Nepal reported that patients with a higher education level, higher income, and age above 40 years were found more likely to use CAM. ${ }^{21}$ Some CAM studies in arthritis reported majority of CAM users in age group of less than 57 years. ${ }^{16}$ In contrast in our study majority (77\%) of CAM users were above 60 years of age group. This can be explained by use of cheap easily available home remedies by elderly who are financially dependent and the least attended in their family. The 2002 NHIS results also indicated that CAM use increases in with age. Barnes et al found that the greatest prevalence of all types of CAM use $(70.3 \%)$ was found among those in eldest age group ( 85 years and older). ${ }^{22}$

\section{CONCLUSION}

Use of CAM is quite prevalent in patients suffering from orthopaedic disorders. Folk remedies and Ayurvedic medicines are most frequently used. Women, elderly and illiterate are more likely to use CAM. The fact that most 
users do not inform their doctors about use of CAM needs attention. The treating doctors should positively ask the history of CAM to their patients so as to avoid unwanted drug interactions and adverse reactions resulting from them.

Funding: No funding sources

Conflict of interest: None declared

Ethical approval: The study was approved by the Institutional Ethics Committee

\section{REFERENCES}

1. What Is Complementary and Alternative Medicine? Available at nccih.nih.gov/ sites/nccam.nih.gov/files/D347_05-25-2012.pdf.

Accessed on 15 March 2016.

2. Bodeker G, Kronenberg F. A public health agenda for traditional, complementary, and alternative medicine. American Journal of Public Health. 2002;92(10):1582-91.

3. Shafiq N, Gupta M, Kumari S, Pandhi P. Prevalence and pattern of use of complementary and alternative medicine (CAM) in hypertensive patients of a tertiary care center in India. Int J Clin Pharmacol Ther. 2003;41(7):294-8.

4. Kumar D, Chandel JK, Bhardwaj AK, Raina SK, Sharma YK. Rationale of integration of complementary and alternative medicine (cam) health facilities in non communicable disease (ncds) surveillance, North India. J Community Med Health Educ. 2012;2:147-8.

5. Hu Z, Yang X, Ho PC, Chan SY, Heng PW, Chan E, et al. Herb-drug interactions: a literature review. Drugs. 2005;65(9):1239-82.

6. Herman CJ, Allen P, Hunt WC, Prasad A, Brady TJ. Use of complementary therapies among primary care clinic patients with arthritis. Prev Chronic Dis. 2004;1(4):1-15.

7. Callahan LF, Exley EK, Mielenz TJ, Brady TJ, Xiao C, Currey SS, et al. Use of complementary and alternative medicine among patients with arthritis. Prev Chronic Dis. 2009;6(2):44.

8. Mbada CE, Adeyemi TL, Adedoyin RA. Prevalence and modes of complementary and alternative medicine use among peasant farmers with musculoskeletal pain in a rural community in SouthWestern Nigeria. BMC Complementary and Alternative Medicine. 2015;15:164.

9. Shenfield G, Lim E, Allen H. Survey of the use of complementary medicines and therapies in children with asthma. J Paediatr Child Health. 2002;38(3):252-7.

10. Raosoft Inc. Available at http:// www.raosoft.com / samplesize.html. Accessed on 12 May 2016.
11. Wang BR, Choi IY, Kim KJ, Kwon YD. Use of traditional Korean medicine by patients with musculoskeletal disorders. PLoS ONE. 2013;8(5):e63209.

12. Jadhav MP, Jadhav PM, Shelke P, Sharma Y, Nadkar M. Assessment of use of complementary alternative medicine and its impact on quality of life in the patients attending rheumatology clinic, in a tertiary care centre in India. Indian $\mathrm{J}$ Med Sci. 2011;65:50-7.

13. Rao JK, Mihaliak K, Kroenke K, Bradley J, Tierney WM, Weinberger M. Use of complementary therapies for arthritis among patients of rheumatologists. Ann Intern Med. 1999;131(6):40916.

14. Zochling J, March JM, Lapsley H, Cross M, Tribe $\mathrm{K}$, Brooks P. Use of complementary medicines for osteoarthritis a prospective study. Ann Rheum Dis. 2004;63:549-54.

15. Ulusoy A, Guçer T, Aksu M, Arslan S, Habiboglu A, Akgol G, et al. The use of complementary and alternative medicine in turkish patients with rheumatic diseases. Archives Rheumatology. 2012;27:31-7.

16. Exley EK, Mielenz TJ, Norton EC, Callahan LF. Complementary and alternative medicine use in musculoskeletal disorders: does medical skepticism matter? Open Rheumatology Journal. 2007;1:5-11.

17. Roy V, Gupta M, Ghosh RK. Perception, attitude and usage of complementary and alternative medicine among doctors and patients in a tertiary care hospital in India. Indian Journal of Pharmacology. 2015;47:137-42.

18. Zaman T, Agarwal S, Handa R. Complementary and alternative medicine use in rheumatoid arthritis: An audit of patients visiting a tertiary care centre. Natl Med J India. 2007;20:236-9.

19. Eisenberg DM, Davis RB, Ettner SL, Appel S, Wilkey S, Van RM, Kessler RC. Trends in alternative medicine use in the United States, 19901997: results of a follow-up national survey. Am Med Asso. 1998;280:1569-75.

20. Wootton JC, Sparber A. Surveys of complementary and alternative medicine: part I. General trends and demographic groups. J Altern Complement Med. 2001;7:195-208.

21. Kadayat T, Bist G, Parajuli A, Karki R Kaundinnyayana A, Dhami N. Patterns and perception of complementary and alternative medicine use by patients in western Nepal. Jour of Publ Heal. 2012;20:297-303.

22. Barnes PM, Griner PE, Mcfann K, Nahin RL. Complementary and alternative medicine use among adults: United States, 2002. Adv Data. 2004;27(343):1-19.

Cite this article as: Gohil NJ, Patel VJ. Use of complementary and alternative medicines by patients with orthopaedic disorders in western part of India: a cross sectional study. Int J Basic Clin Pharmacol 2016;5:1722-6. 